\title{
Proposal for greater balance and inclusion in ranking nuclear medicine journals
}

\author{
Malik E. Juweid $^{1} \cdot$ Mark Tulchinsky $^{2} \cdot$ Mones Abu-Asab $^{3} \cdot$ Felix M. Mottaghy $y^{4,5}$ \\ Published online: 6 March 2021 \\ (C) The Author(s), under exclusive licence to Springer-Verlag GmbH, DE part of Springer Nature 2021
}

Nuclear medicine journals (NMJs) are usually ranked in the category of radiology, nuclear medicine and imaging by the two largest citation indices, the Web of Science (WoS) and Scopus (https://www.researchgate.net/publication/ 342803832_2020_Latest_Impact_Factor_Clarivate_ Analytics_Journal_Citation_Reports_Release_of_JCR_ Thomson_Reuters, https://www.scimagojr.com/journalrank. php? category $=2741 \&$ page $=4 \&$ total_size $=335$ ); however, these two indices sometimes produce quite discrepant rankings due to the different algorithms used for calculating their rankings. For example, the Clinical Nuclear Medicine journal is ranked third out of 17 NMJs ranked by WoS in 2019 but drops to the eleventh position out of the 29 NMJs ranked by Scopus in the same year. In contradistinction, the European Journal of Nuclear Medicine and Molecular Imaging Physics is ranked fourth by the Scopus while it drops to the tenth position on the WoS listing. While the WoS ranking is widely recognized, Scopus index is more inclusive, ranking a larger number of journals, which is especially helpful for up-and-coming journals and those from developing countries. We propose a potential ranking method

This article is part of the Topical Collection on Editorial

Malik E. Juweid

mjuweid@yahoo.com

1 Division of Nuclear Medicine/Department of Radiology and Nuclear Medicine, University of Jordan, Queen Rania Street Al Jubeiha, Amman 11942, Jordan

2 Department of Radiology, Penn State University Hershey Medical Center, Hershey, PA, USA

3 Section of Histopathology, National Eye Institute, the National Institute of Health, Bethesda, MD, USA

4 Department of Nuclear Medicine, University Hospital, RWTH University, Aachen, Germany

5 Department of Radiology and Nuclear Medicine, Maastricht Medical Center, Maastricht, Netherlands of NMJ combining the WoS and Scopus rankings for 2019 (https://www.researchgate.net/publication/342803832_2020_ Latest_Impact_Factor_Clarivate_Analytics_Journal_ Citation_Reports_Release_of_JCR_Thomson_Reuters, https://www.scimagojr.com/journalrank.php?category= 2741\&page $=4 \&$ total_size $=335$ ).

According to the proposed ranking, the NMJs are first ranked according to each database separately followed by calculating the average of the two ranks for each journal to determine the new "combined rank" (Table 1). For those NMJ ranked by Scopus but not WoS, a WoS rank for all unranked NMJ that is one rank higher than the lowest WoS rank is used. For example, 29 NMJs are currently ranked by Scopus while only 17 by WoS. Thus, all 12 NMJs unranked by WoS will receive a WoS rank of 18 enabling the calculation of generally low average rank reflecting the unranked status by WoS. While this approximation may underestimate the true merit of a Scopus-ranked/WoS-unranked journal, this approach is sufficiently simple, transparent, and perhaps even objective in the absence of large studies 
Table 1 Proposed balanced ranking of nuclear medicine journals based on combined Web of Science (WoS) and Scopus rankings

\begin{tabular}{|c|c|c|c|c|}
\hline $\begin{array}{l}\text { Journal combined } \\
\text { rank (2019) }\end{array}$ & Journal & $\begin{array}{l}\text { Scopus rank } \\
(2019)\end{array}$ & $\begin{array}{l}\text { WoS rank } \\
(2019)\end{array}$ & $\begin{array}{l}\text { Average rank } \\
(2019)\end{array}$ \\
\hline 1 (tie) & European Journal of Nuclear Medicine and Molecular Imaging & 1 & 2 & 1.5 \\
\hline 1 (tie) & Journal of Nuclear Medicine & 2 & 1 & 1.5 \\
\hline 3 & Seminars in Nuclear Medicine & 5 & 4 & 4.5 \\
\hline 4 & Molecular Imaging and Biology & 7 & 6 & 6.5 \\
\hline 5 (tie) & Clinical Nuclear Medicine & 11 & 3 & 7 \\
\hline 5 (tie) & Journal of Nuclear Cardiology & 9 & 5 & 7 \\
\hline 5 (tie) & EJNMMI Research & 6 & 8 & 7 \\
\hline 5 (tie) & EJNMMI Physics & 4 & 10 & 7 \\
\hline 9 (tie) & Molecular Imaging & 10 & 7 & 8.5 \\
\hline 9 (tie) & Annals of Nuclear Medicine & 8 & 9 & 8.5 \\
\hline 11 & American Journal of Nuclear Medicine and Molecular Imaging & 3 & Unranked & 10.5 \\
\hline 12 & Nuclear Medicine and Biology & 13 & 11 & 12 \\
\hline 13 & Cancer Biotherapy and Radiopharmaceuticals & 14 & 12 & 13 \\
\hline 14 & Nuclear Medicine Communications & 15 & 14 & 14.5 \\
\hline 15 & Clinical and Translational Imaging & 12 & Unranked & 15 \\
\hline 16 & Quarterly Journal of Nuclear Medicine and Molecular Imaging & 18 & 13 & 15.5 \\
\hline 17 (tie) & Nuklearmedizin-Nuclear Medicine & 19 & 15 & 17 \\
\hline 17 (tie) & PET clinics & 16 & Unranked & 17 \\
\hline 19 & Nuclear Medicine Molecular Imaging & 17 & Unranked & 17.5 \\
\hline 20 & Journal of Radioanalytical and Nuclear Chemistry & 20 & Unranked & 19 \\
\hline 21 & Molecular Imaging and Radionuclide Therapy & 21 & Unranked & 19.5 \\
\hline 22 (tie) & Hellenic Journal of Nuclear Medicine & 24 & 16 & 20 \\
\hline 22 (tie) & Nuclear Medicine Review & 22 & Unranked & 20 \\
\hline 24 & Journal of Nuclear Medicine Technology & 23 & Unranked & 20.5 \\
\hline 25 & Journal of Medical Imaging and Radiation Sciences & 25 & Unranked & 21.5 \\
\hline 26 & Egyptian Journal of Radiology and Nuclear Medicine & 26 & Unranked & 22 \\
\hline 27 & Iranian Journal of Nuclear Medicine & 27 & Unranked & 22.5 \\
\hline 28 (tie) & Médecine Nucléaire & 29 & 17 & 23 \\
\hline 28(tie) & Indian Journal of Nuclear Medicine & 28 & Unranked & 23 \\
\hline
\end{tabular}

comparing the attributes of both rankings against a "gold standard."

The proposed combined ranking will have some advantages. Rather than having $\sim 40 \%$ of NMJs without any rank by the widely used WoS, every NMJ will now receive a rank even if it is sometimes mostly derived from the Scopus rank. This places several WoSunranked journals in the second or third quartile of the new ranking and could prove beneficial to NMJs from developing countries where journals remain WoSunranked for a considerable period of time; any improvement in their SCOPUS ranking will automatically lead to an improved combined ranking that could attract higher quality submissions and subsequently improve their citation impact.
We believe that our proposed ranking approach will be beneficial to all parties involved-readership, authors, and NMJs.

\section{Declarations}

Informed consent Not applicable.

Ethical approval Institutional Review Board approval was not required because the paper is an Editorial.

Conflict of interest The authors declare no competing interests.

Publisher's note Springer Nature remains neutral with regard to jurisdictional claims in published maps and institutional affiliations. 